\title{
GEOMORFOLOGÍA Y ETAPAS \\ DE KARSTIFICACIÓN EN LA RAMA CASTELLANA DEL SISTEMA IBÉRICO
}

\author{
POR

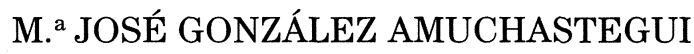

\section{Introducción}

En este trabajo se analizan las distintas etapas de karstificación que ha sufrido un sector de la rama castellana del Sistema Ibérico, estableciéndose un modelo evolutivo para todo el área. Más concretamente, la zona se sitúa en la cuenca alta del Tajo y abarca la superficie ocupada por el triángulo que se extiende entre Peralejos de las Truchas, Molina de Aragón y Huertapelayo (Guadalajara).

Estructuralmente la zona se organiza a partir de los grandes ejes tectónicos de direcciones NW-SE y SW-NE que arman la Cadena; domina un estilo de plegamiento laxo que ha dado lugar a estructuras subhorizontales, cuya suavidad morfológica se ha visto reforzada por la elaboración de una extensa superficie de erosión de edad finiterciaria. Este conjunto se encuentra compartimentado por una serie de profundas hoces y cañones labrados por la red fluvial, en cuyas paredes es frecuente la presencia de numerosas surgencias que drenan los sistemas kársticos aquí analizados. Sin embargo, las características estructurales

M. ${ }^{a}$ José González Amuchastegui. Dpto. de Geografía. Universidad del País Vasco.

Expreso mi agradecimiento al profesor González Martín por la ayuda en la discusión, lectura y corrección de este trabajo.

Estudios Geográficos

Tomo LIX, n. ${ }^{\circ} 232$, julio-septiembre 
y el dominio absoluto de las litologías calizas han dificultado el establecimiento de la red fluvial, frente al desarrollo de una intensa karstificación, caracterizada fundamentalmente por la gran abundancia de las formas endokársticas y en menor medida de las morfologías superficiales.

\section{Objeto y metodología}

El objetivo de este trabajo es el establecimiento de un modelo evolutivo para la karstificación de este sector de la rama castellana del Sistema Ibérico (figura 1). Como consecuencia de la escasez de las formas kársticas superficiales, unida a la dificultad intrínseca que acompaña siempre el estudio del endokarst, hemos recurrido a dos métodos indirectos de análisis para la definición de las etapas de karstificación: el estudio de las acumulaciones tobáceas y del comportamiento kárstico actual mediante el análisis de los caudales y de las aguas de las surgencias

Apoyándonos en la idea del geosistema, hacemos corresponder las etapas de karstificación y las de construcción de edificios tobáceos, de modo que el análisis de estos conjuntos carbonáticos se sitúa en la base de la definición de las etapas de karstificación, asumiendo en definitiva, lo que ha sido definido como una dinámica antagónica de travertinización-erosión (Vaudour, 1984). El reconocimiento de campo, la cartografía y el análisis mineralógico y sedimentológico han permitido el establecimiento de una cronología relativa de los conjuntos tobáceos y de las formas exokársticas, lo que a su vez ha llevado a la definición de las principales fases de karstificación.

Por otro lado, el seguimiento hidroquímico y de los caudales de los manantiales kársticos de la zona han permitido conocer el grado de karstificación, organización y tipo de red de drenaje subterráneo así como la evolución de los sistemas kársticos.

\section{Características geomorfológicas y comportamiento actual del karst}

Existe una íntima relación entre los factores estructurales y el modelado kárstico de la región como queda manifiesto en la función di- 


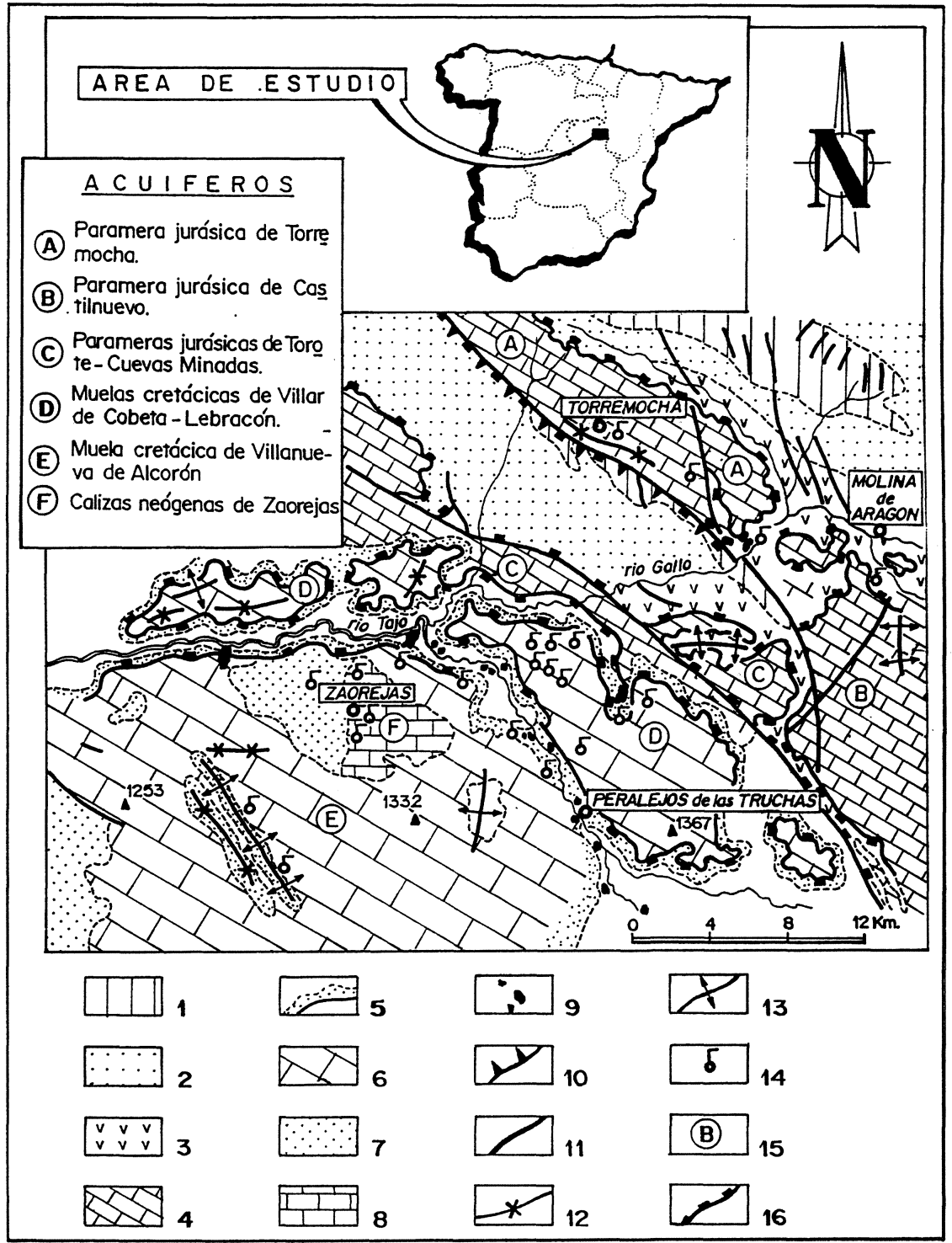

FiguRA. 1.-Mapa de localización. Cartela: 1 Paleozoico. 2 Trías, conglomerados y areniscas. 3 Trías, arcillas y yesos. 4 Jurásico, calizas y margas. 5 Cretácico, arenas. 6 Cretácico, dolomías y calizas. 7 Terciario, conglomerados. 8 Terciario, calizas.

9 Tobas cuaternarias. 10. Cabalgamientos. 11. Falla. 12 Sinclinal. 13 Anticlinal. 14 Surgencia. 15 Acuífero. 16. Reborde de paramera o muela. 
rectriz ejercida por la tectónica en la evolución de las principales morfologías: formas asociadas a grandes ejes sinclinales, depresiones tectónicas, fallas, etc., o la establecida por la fracturación al facilitar la penetración del agua en la masa calcárea favoreciendo la disolución.

Litológicamente, la presencia de materiales asociados a las facies Keuper en las parameras jurásicas y Utrillas en las muelas cretácicas, constituyendo los basamentos impermeables de los conjuntos kársticos de la zonas, han obstaculizado el desarrollo de las redes kársticas en profundidad. Pero además, la frecuente presencia de niveles margosos intercalados en las diferentes unidades jurásicas (figura 2) y en menor medida en las cretácicas, así como la acentuada estratificación que presentan los distintos pisos, parecen haber impedido «a priori», el desarrollo de una morfología kárstica de importancia; ésta ha visto de continuo interrumpida su evolución por niveles locales de baja permeabilidad lo que ha dado lugar a la presencia de pequeñas «capas acuíferas». Es precisamente este hecho el que explica la mayor profusión de manifestaciones kársticas en los tramos dolomíticos del Cretácico superior, Senoniense y Turoniense más concretamente, caracterizados por su masividad o estratificación en capas gruesas y donde son muy frecuentes las cavidades, simas, depresiones de forma indefinida, algunas dolinas y el poljé de Villanueva de Alcorón; en el resto de las formaciones apenas podemos hablar de formas exokársticas de entidad, puesto que en la mayor parte de los casos se trata de morfologías cuya falta de definición, depresiones de contornos irregulares y escasa profundidad, plantea serias dudas a la hora de su clasificación, resultando más preciso al referirnos a la karstificación, hablar de una percolación difusa a partir de las múltiples fracturas y poros de las grandes masas calizas.

En cuanto a la organización geomorfológica hay que señalar que el encajamiento realizado por la red fluvial del Tajo, ha individualizado una serie de conjuntos kársticos que se asocian a materiales jurásicos y cretácicos (figura 1); el modo de funcionamiento se incluye dentro del karst de tipo «autogénico», en el que los acuíferos se encuentran desconectados entre sí y colgados altimétricamente con respecto a la red fluvial regional que ha excavado sus valles en los materiales impermeables; en definitiva, la recarga hidrológica procede de las aguas de infiltración caídas sobre las superficies calizas dominantes, y las descargas se realizan a través de los manatiales situados a distintas cotas en 


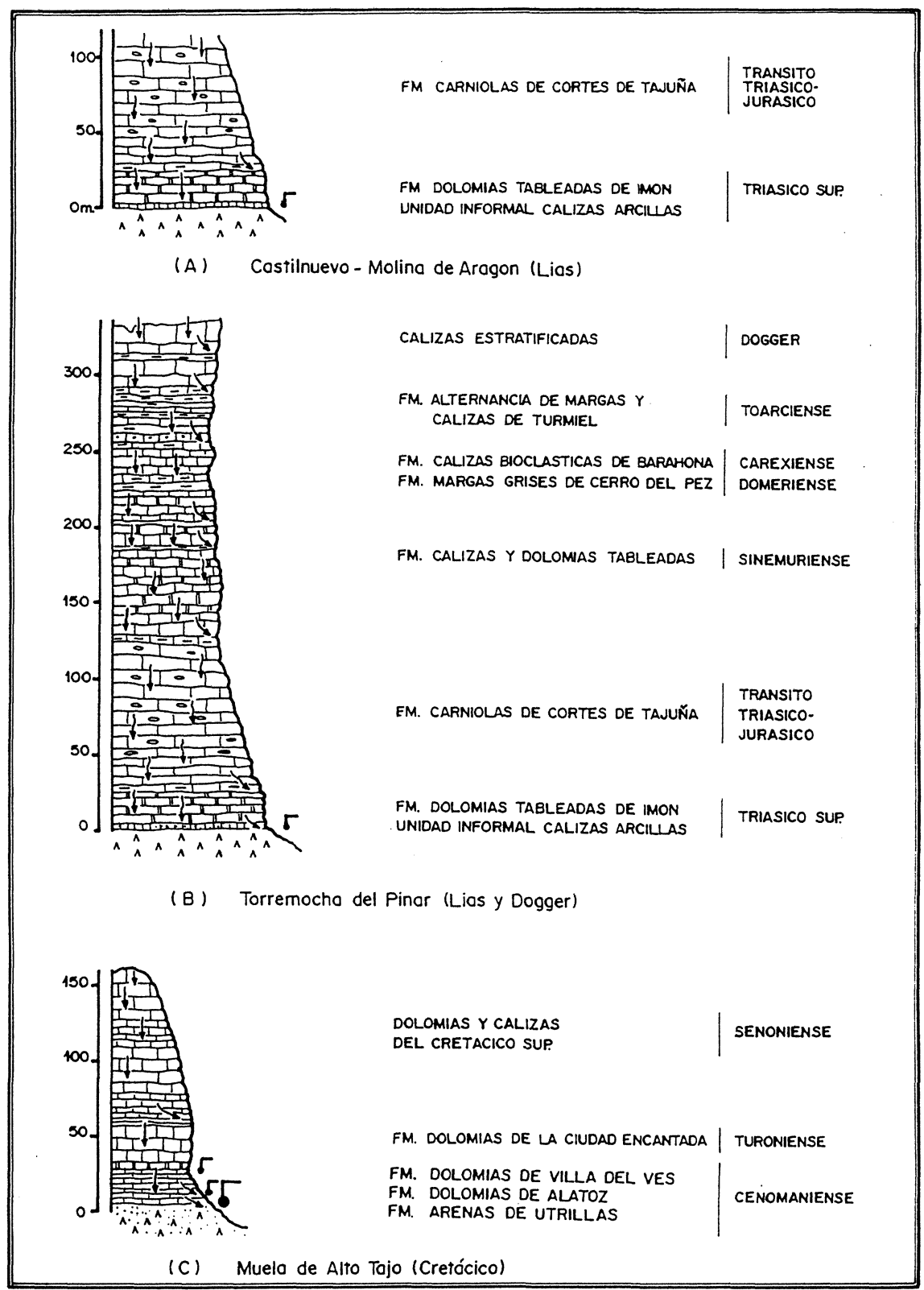

FIGURA. 2.-Tipología de columnas estratigráficas. 
las laderas como consecuencia de la presencia de los niveles de baja permeabilidad antes mencionados.

Dentro de estos acuíferos se establece la existencia de una red kárstica con superposición de redes correspondientes a diversos estadios de descenso del nivel de base, relacionada directamente con el encajamiento de la red fluvial; de este modo se explica el escalonamiento de las surgencia en las laderas, asociadas a las cuales aparecen asimismo diversas acumulaciones tobáceas en distintas posiciones altimétricas.

Los análisis hidrológicos e hidroquímicos de las aguas de las surgencias que drenan los acuíferos de este sector han permitido establecer una diferenciación en el comportamiento kárstico de los acuíferos jurásicos y cretácicos (González Amuchastegui, García Giménez y González Martín, 1995), de modo que mientras los jurásicos (Torremocha, Castilnuevo-Molina, Torete-Cuevas Minadas) se asocian a los acuíferos difusos -alta permeabilidad con escasez de formas de absorción, recarga uniforme, importante capacidad de almacenamiento y circulación muy lenta de las aguas-, los cretácicos, y sobre todo la muela de Villanueva, se comporta como un acuífero bicarbonatado de fisuración y grado de karstificación intermedio: sistema de infiltración rápido a partir de un desarrollo espeleológico considerable, pero flujo lento en profundidad, asimilable a la dinámica de los difusos. Finalmente, hay que señalar la existencia de otros acuíferos de alta fisuración, aunque de menor representación en nuestra zona, como es el caso de la Escareruela, con un drenaje de respuesta rápida y brusca, con fuertes pulsaciones.

Como se ha comentado, los conductos endokársticos, simas fundamentalmente, son los principales conjuntos de disolución de nuestro ámbito de estudio, a pesar de lo cual no presentan un desarrollo importante ni en profundidad, la sima de Manuel Mozo con $142 \mathrm{~m}$. de profundidad explorada es la mayor (Puch, 1988), ni lateralmente. Estas formas se asocian sobre todo a los materiales del Cretácico superior y más concretamente a las dolomías masivas y calizas dolomíticas del Senoniense y Turoniense, llegando a atravesar en algunos casos el tramo basal de tránsito hacia el Cenomaniense (Puch, 1986); de un modo más puntual, aparecen algunos ejemplos asociados a los estratos jurásicos. Cuatro son los factores estructurales que más directamente inciden en la génesis y evolución de las cavidades de la región: 
La fracturación en tanto que constituyen puntos de absorción preferencial a partir de los cuales se inician los procesos de disolución, ensanchamiento de diaclasas, dirigiendo además, la disposición de las simas (simas Bustal I, II y III, de la Muela, etc.). Por otro lado, el trazado interno de la cavidad viene determinado en gran medida por este mismo factor que «guía» la dirección de los conductos, el recorrido de los posibles meandros, conductos con predominio de la componente vertical, etc.

El buzamiento de los estratos influye decisivamente en el desarrollo de las cavidades y en su trazado, ya que favorece o dificulta la penetración del agua de escorrentía (sima del Basurero)

Las juntas de estratificación y el distinto grado de resistencia de los materiales frente a la erosión son los otros dos factores que intervienen en el trazado y desarrollo de las simas y cavidades, de tal modo que la erosión diferencial sobre la roca encajante dará lugar a discontinuidades y salientes con laminadores en las zonas de rocas más competentes, frente a morfologías caóticas predominantes sobre las más deleznables; a partir de los planos de estratificación, el agua encuentra áreas de circulación preferencial desarrollando en muchos puntos bóvedas planas.

\section{Los depósitos tobáceos como acumulaciones correlativas a las etapas de karstificación en la zona}

Como ya se dijo en la introducción, las acumulaciones tobáceas constituyen testimonios indirectos de una circulación kárstica. Efectivamente, existe una estrecha relación entre el karst y los travertinos de surgencia; éstos se construyen a partir de los carbonatos que marchan disueltos en las aguas que han adquirido su alto grado de mineralización en el karst profundo. Se trata por tanto de depósitos correlativos de importantes fases de karstificación que han alternado en esta zona con otros períodos climáticos fríos y en ocasiones relativamente secos; la disposición escalonada, a diversas alturas en las laderas de los valles de los diferentes depósitos tobáceos, permiten seguir no sólo la evolución kárstica del sector, sino también establecer la paleohidrodinámica de estos manantiales, su cronología y el descenso de los niveles kársticos vinculados al encajamiento de la red fluvial del Tajo. 
Las formaciones tobáceas asociadas a surgencias kársticas aparecen repetidamente representadas en este sector del Alto Tajo (figura 3). Unas veces se sitúan al pie o en las proximidades de los manantiales y otras en las cercanías de la desembocadura de pequeños arroyos que encuentran su origen en surgencias y manantiales kársticos y cuyo régimen por tanto se halla en estrecha relación con la dinámica del karst. Asimismo, su ubicación se asocia reiterativamente al contacto entre litologías de permeabilidad marcadamente diferente: arcillas y margas de facies Keuper con dolomías liásicas; arenas del Albiense con calizas y dolomías cenomanienses, capas calizas con bancos de permeabilidad más reducida, y que actúan como niveles para-freáticos locales, a partir de los cuales las aguas se concentran para aflorar en superficie. Estas han adquirido su contenido hidroquímico a partir de la disolución de las masas carbonatadas atravesadas subterráneamente procedentes de las amplias plataformas calcáreas que se extienden por todo este sector.

Una vez en superficie las aguas sufren una serie de modificaciones bio-físico-químicas que rompen el equilibrio de las soluciones produciendo la precipitación de carbonatos. En este proceso incide de un modo importante, como ya ha sido señalado, la presencia de los yesos del Trías superior y de las dolomías jurásicas y cretácicas, ya que la liberación de sulfatos y magnesio procedentes de ambas litologías, controlan la solubilidad de las soluciones, favoreciendo tanto la precipitación físico-química como la biológica de los carbonatos (Nicod, 1981 y 1986; González y otros, 1987).

El estudio detallado de las acumulaciones tobáceas del Alto Tajo, ha permitido definir las principales etapas de karstificación de la zona, al ser entendidas como depósito correlativo de la circulación kárstica (Magnin, F., Guendon, J. L., Vaudour, J. et Martín, P.,1991). Por otro lado, la situación estratigráfica de estas acumulaciones, en relación con otros depósitos de significado climático contrastado (coluviones crioclásticos), nos ha permitido establecer, de un modo aún más riguroso, un modelo evolutivo para todo el área.

\section{Principales etapas de karstificación}

En cuanto a la caracterización de los momentos propicios para la karstificación hay que señalar que los períodos más fríos del Pleistoceno 


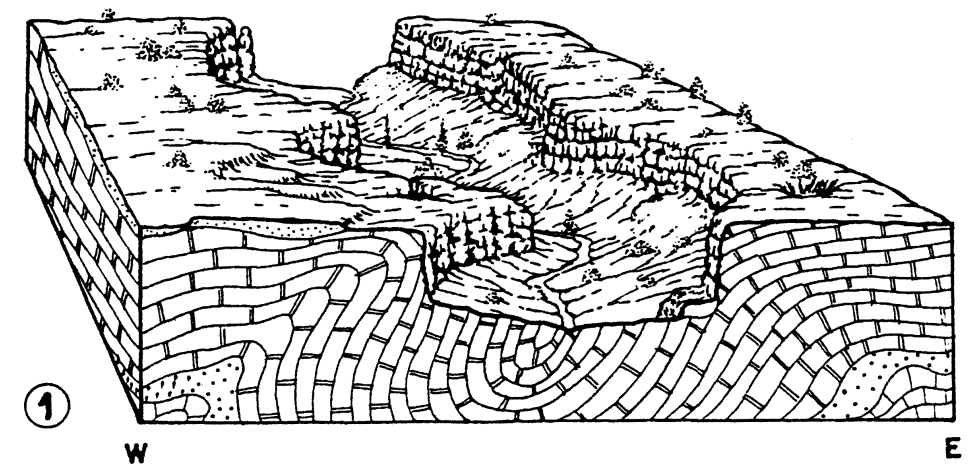

(2)

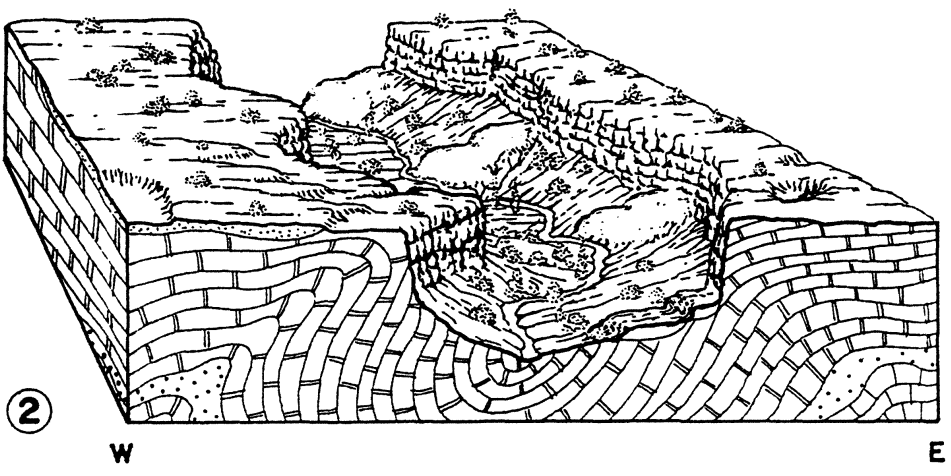

(3)

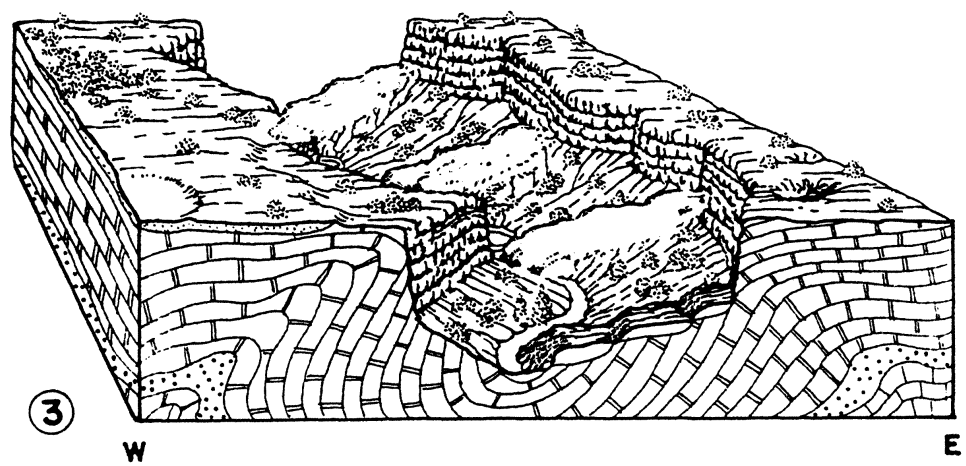

FiguRA. 3.-Fases de encajamiento en el valle del Tajo y formación de edificios tobáceos: 1. Pleistoceno. 2. Pleistoceno medio 3. Holoceno.

$$
-431-
$$


no han sido favorables para el desarrollo de las formas kársticas, ni tampoco para la construcción de edificios tobáceos. En primer lugar porque la agresividad de las aguas está controlada por la presencia de $\mathrm{CO}_{2}$ y es un hecho demostrado que en los ambientes fríos, tanto en el hielo de las lenguas glaciares (Ek, 1966), como en las capas nivales (Miotke, 1968), la presencia de $\mathrm{CO}_{2}$ apenas sobrepasa el valor de $0,018 \%$, cuando en condiciones atmosféricas normales alcanza $0,03 \%$. Así pues, una conclusión preliminar es que las aguas de fusión de nieve tienen un potencial de agresividad generalmente muy bajo, por lo que las concentraciones que ofrecen sus aguas son siempre bajas $\left(<100 \mathrm{mg} / \mathrm{l}\right.$ de $\mathrm{CO}_{3} \mathrm{Ca}-\mathrm{CO}_{3} \mathrm{Mg}$ ).

En segundo lugar, porque estos períodos han jugado negativamente en los procesos kársticos, y ello por dos factores fundamentales:

- La rareza o ausencia de vegetación ha impedido incrementar la agresividad de disolución de las aguas dada la escasa producción de $\mathrm{CO}_{2}$ y de ácidos orgánicos a partir de la capa humífera.

- En estas condiciones, la débil mineralización de las aguas también constituye un obstáculo en la construcción tobácea.

- Finalmente, los efectos de los ciclos de hielo-deshielo son muy propicios a la obturación de los conductos kársticos y dificultan el desarrollo de los procesos kársticos.

Por tanto, hacemos corresponder la edificación de tobas y karstificación con momentos climáticos lluviosos y con cubiertas edáficas y vegetales propicias a la alimentación de $\mathrm{CO}_{2}$. En esta dirección, períodos de activísima fitoedafoestabilización, apunta la presencia de acumulaciones tobáceas fluviales apoyadas en los fondos de los valles labrados sobre el Keuper o en los cañones labrados en el Buntsandstein.

En el dominio mediterráneo, la karstificación ha conocido una evolución muy compleja y por ello es muy arriesgado definir un esquema preciso. Pueden establecerse dos grandes etapas karstogénicas bien definidas y totalmente diferentes en función del nivel de base: una de edad neógena y otra cuaternaria-holocena.

Etapas kársticas neógenas. Se vinculan a fases desarrolladas con posterioridad a la orogenia alpina, y entre ellas destacamos:

- Una primera etapa de edad miocena. Los principales testimonios de este momento se asocian al conjunto de capas tobáceas situadas 
en las proximidades de Zaorejas formadas por elementos bioconstruidos (facies de tubos verticalizados, tumbados en la dirección de la corriente) y lechos detríticos de naturaleza calcarenítica. Estos niveles carbonáticos, situados altimétricamente muy cerca de la superficie de erosión y también al igual que los estratos mesozoicos, arrasados por ella, constituyen a escala regional, los primeros vestigios de una disolución generalizada sobre las parameras y muelas mesozoicas de la región, cuyas aguas cargadas de carbonatos avanzaron por un conjunto de redes kársticas de trazado poco verticalizado con aguas freáticas que estaban muy cerca de la plana topografía culminante.

- Una segunda, de edad plio-cuaternaria. Sus testigos son también de naturaleza tobácea y se vinculan a la serie de afloramientos que determinan los paisajes tabulares de los alrededores de Prados Redondos, Molina de Aragón, Valhermoso, etc.; su morfología, geometría de lechos y estructuras y tipo de facies carbonáticas señalan una dinámica fluvial con escaso arrastre de terrígenos y donde la procedencia de los carbonatos se vincularía a intensos fenómenos de disolución ejercidos sobre la paramera jurásica de la zona, con aportes de procedencia esencialmente suroriental. Es posible que a esta edad, tal y como lo han sugerido algunos autores, se vincule la etapa de karstificación que actuó en los estratos paleozoicos de la Sierra Menera y que dió lugar a la génesis de los yacimientos de hierro allí ubicados, si bien no se descarta que ésta haya comenzado con anterioridad y continuado en períodos posteriores e incluso recientes del Cuaternario (Fernández Nieto et al., 1983).

Es una hipótesis defendida desde hace ya bastantes años, que en el mundo mediterráneo, tanto oriental (Vaumas, 1967) como occidental (Lhenaff, 1988), los tiempos del Villafranquiense inferior han sido climáticamente los más adecuados para la karstificación. En el contexto regional del Sistema Ibérico, la principal etapa de karstificación se ubicó cronológicamente en el Plioceno o tránsito Plioceno-Cuaternario (Gutiérrez y Peña, 1975 y 1979). En efecto, además de las condiciones ambientales propicias para la disolución, se registró la etapa distensiva finipliocena de abombamiento en unos parajes y de fracturación en otros, con apertura de un sistema de fosas tectónicas. Ambos acontecimientos -climático y estructural- facilitaron la iniciación y más tarde el desarrollo de un conjunto de formas kársticas; ésta sería la fase 
responsable de la génesis de los grandes poljés de la Cordillera Ibérica (Gutiérrez Elorza y Peña, 1989; Alonso, González Martín y Ugarte, 1987).

Es muy posible que en esta etapa se originaran tanto las depresiones del área de Zaorejas como el poljé de Villanueva de Alcorón (controlado por fallas de dirección ENE-WSW) que se instalan sobre la superficie de erosión pliocena, cuyas inmediaciones altimétricas sirvieron de nivel de base kárstico a todos los procesos que de esta índole se registraron antes del encajamiento de la red fluvial.

Etapas kásrticas Cuaternarias y Holocenas. Durante el Cuaternario, la karstificación continuó con mayor o menor intensidad según las peculiaridades paleoclimáticas de los distintos períodos. Esta karstificación fue dirigida por el progresivo encajamiento de la red fluvial del Tajo y sus afluentes, cuyos cauces fueron controlando la posición altimétrica de los niveles kársticos; coincidiendo con las etapas de lenta incisión fluvial, y por tanto estabilización de los niveles de base kársticos, los conductos subterráneos de la red de drenaje se caracterizaban por sus trazados subhorizontales o de poca pendiente; a ello contribuyó en buena medida, la disposición subtabular de las capas geológicas que arman algunas parameras jurásicas y el escaso buzamiento que ofrecen los estratos cretácicos en las muelas. Por otro lado, las fases de fuerte encajamiento de los cauces fluviales impusieron los trazados verticalizados a los conductos del karst regional y la profundización de las simas.

La precariedad y aspecto no funcional de las formas subáereas y el escaso conocimiento que tenemos de las redes subterráneas, así como su compleja evolución en el tiempo, nos obligan a recurrir a los aterrazamientos de la red fluvial del Tajo y a las acumulaciones tobáceas como únicos elementos con los que establecer un modelo evolutivo, necesariamente simplificado y provisional en ausencia de dataciones isotópicas que sólo han sido aplicadas por otros autores al conjunto del Puente San Pedro (López Vera y Martínez Goytre, 1989).

Los aluviones fluviales serán los testigos que sugieran la posición de los niveles de base locales y su relación altimétrica con los de origen kárstico y las acumulaciones tobáceas serán, tal y como ya hemos señalado, los sedimentos correlativos a acciones kársticas más o menos importantes en la región. 
- Pleistoceno antiguo. Este modelo evolutivo que se va a desarrollar tras el encajamiento de la red fluvial tiene como la etapa más antigua, la que originó la gran barrera travertínica construida por las aguas del Tajo (sector Majadal Bajero), situada a $+200 \mathrm{~m}$. sobre el cauce actual (González Amuchastegi y González Martín, 1997). La edificación de una barrera de estas condiciones exige unas condiciones geoambientales muy precisas: aguas del Tajo cargadas de gran cantidad de materiales disueltos aportados por las surgencias kársticas de aquel momento; escasez de terrígenos y materiales en suspensión, caudales sin fuertes pulsaciones de corriente, etc. Estas condiciones identifican un período muy húmedo con activa fitoestabilización de las vertientes en el que se estaba produciendo la karstificación del techo de las parameras y muelas, y cuyos componentes disueltos surgían por los manantiales y construían masas de toba a su pie, a pesar de lo cual no hemos podido identificar ninguna acumulación de este tipo asociada a este momento.

La existencia de un régimen fluvial muy regular pudo deberse a un régimen de precipitaciones no tan irregular como el actual, sin embargo es más posible que se debiera a la existencia de flujos subterráneos muy lentos y regularizados, dada la escasa karstificación que debía presentar el conjunto de muelas y parameras. Cronológicamente, y a modo de hipótesis, ubicamos esta fase en el Pleistoceno antiguo.

Con posterioridad, el cauce del Tajo y de sus afluentes, desencadenaron una potente y prolongada acción de encajamiento que guió sin duda, el desarrollo de la red subterránea y conllevó el progresivo descenso de los niveles de base kársticos. Con el paso del tiempo, esta incisión fluvial alcanzó en muchas zonas, los materiales impermeables del Cretácico medio (Facies Utrillas) o los del Triásico Superior (Facies Keuper), y más tarde volvió a encajarse en ellos, lo que determinó que una gran parte de las surgencias se localicen por encima de la cota de los talwegs.

La presencia escalonada de las acumulaciones tobáceas asociadas a las paleosurgencias y su cronología (generalmente las más antiguas dispuestas en los replanos más elevados y las más modernas ubicadas a pocos metros de los cauces) indican una evolución polifásica; se han detectado un conjunto de generaciones que se repiten en las distintas unidades kársticas definidas, destacan las siguientes fases (cuadro I): 


\section{Cuadro I}

SÍNTESIS DE LOS RASGOS GEOMORFOLÓGICOS

Y GENERACIONES TOBÁCEAS

\begin{tabular}{|c|c|c|c|c|c|c|c|}
\hline \multirow{2}{*}{$\begin{array}{l}\text { Unidad } \\
\text { extensión }\end{array}$} & \multirow{2}{*}{$\begin{array}{c}\text { Formas } \\
\text { exokársticas }\end{array}$} & \multirow{2}{*}{$\begin{array}{c}\text { Formas } \\
\text { endokársticas }\end{array}$} & \multicolumn{5}{|c|}{$\begin{array}{l}\text { Principales surgencias y generaciones } \\
\text { tobáceas asociadas (volumen) }\end{array}$} \\
\hline & & & & $\begin{array}{c}\text { Pleisto- } \\
\text { ceno } \\
\text { Medio }\end{array}$ & $\begin{array}{c}\text { Recien- } \\
\text { te }\end{array}$ & $\begin{array}{l}\text { Holo- } \\
\text { ceno }\end{array}$ & Actual \\
\hline $\begin{array}{l}\text { Jurásico de } \\
\text { Torremocha } \\
\left(87 \mathrm{~km}^{2}\right)\end{array}$ & $\begin{array}{l}\text { Lapiaz poco } \\
\text { desarrollado. } \\
\text { Pequeñas } \\
\text { depresiones }\end{array}$ & $\begin{array}{l}\text { Cavidades } \\
\text { de escasa } \\
\text { longitud }\end{array}$ & $\begin{array}{l}\text { F. Puzuelo } \\
\text { F. Mazo } \\
\text { F. Hernando }\end{array}$ & 3 & $\begin{array}{l}1 \\
2\end{array}$ & $\begin{array}{l}1 \\
2\end{array}$ & $\begin{array}{l}1 \\
1\end{array}$ \\
\hline $\begin{array}{l}\text { Jurásico de } \\
\text { Castilnuevo } \\
\left(240 \mathrm{~km}^{2}\right)\end{array}$ & $\begin{array}{l}\text { Lapiaz poco } \\
\text { desarrollado. } \\
\text { Pequeñas } \\
\text { depresiones }\end{array}$ & $\begin{array}{l}\text { Cavidades } \\
\text { de escasa } \\
\text { longitud }\end{array}$ & $\begin{array}{l}\text { F. Rinconcillo } \\
\text { F. El Caserío } \\
\text { F. Las Alreras }\end{array}$ & & $\begin{array}{l}2 \\
2 \\
2\end{array}$ & 2 & 1 \\
\hline $\begin{array}{l}\text { Jurásico de } \\
\text { Torete-Cuevas } \\
\text { Minadas } \\
\left(83 \mathrm{~km}^{2}\right)\end{array}$ & $\begin{array}{l}\text { Lapiz poco } \\
\text { desarrollado. } \\
\text { Pequeñas } \\
\text { depresiones }\end{array}$ & $\begin{array}{l}\text { Cavidades } \\
\text { de escasa } \\
\text { longitud }\end{array}$ & $\begin{array}{l}\text { F. El Mingazo } \\
\text { F. El Hontanar }\end{array}$ & & & & $\begin{array}{l}1 \\
1\end{array}$ \\
\hline $\begin{array}{l}\text { Cretácico de } \\
\text { Villar de } \\
\text { Cobeta } \\
\left(111 \mathrm{~km}^{2}\right)\end{array}$ & $\begin{array}{l}\text { Lapiz poco } \\
\text { desarrollado. } \\
\text { Pequeñas } \\
\text { depresiones }\end{array}$ & $\begin{array}{l}\text { Simas y cuevas } \\
\text { de escaso } \\
\text { desarrollo: } \\
\text { (C. Hoya del } \\
\text { Castillo, } \\
\text { C. sima San } \\
\text { Cristóbal) }\end{array}$ & $\begin{array}{l}\text { F. El Contadero } \\
\text { F. El Ruidero } \\
\text { F. El Ventorro }\end{array}$ & & 3 & 2 & $\begin{array}{l}1 \\
1 \\
1\end{array}$ \\
\hline $\begin{array}{l}\text { Cretácico de } \\
\text { Villanueva } \\
\text { de Alcorcón } \\
\text { y neógeno de } \\
\text { Zaorejas } \\
\left(466 \mathrm{~km}^{2}\right)\end{array}$ & $\begin{array}{l}\text { Disolución } \\
\text { en diaclasas. } \\
\text { Poljé de } \\
\text { Villanueva } \\
\text { de Alcorcón. } \\
\text { Depresiones }\end{array}$ & $\begin{array}{l}\text { Abundantes } \\
\text { simas (Bustal I, } \\
\text { II, III, La Raja, } \\
\text { Manuel Mozo, } \\
\text { Orna, del } \\
\text { Agujero) }\end{array}$ & $\begin{array}{l}\text { F. El Campillo } \\
\text { F. de Las Tobas } \\
\text { F. de Armallones } \\
\text { F. de la Vega }\end{array}$ & 3 & $\begin{array}{l}3 \\
2 \\
2 \\
2\end{array}$ & $\begin{array}{l}3 \\
2 \\
2 \\
2\end{array}$ & $\begin{array}{l}2 \\
1 \\
1 \\
1\end{array}$ \\
\hline
\end{tabular}

1, 2 y 3: Escala de volumen de los edificios tobáceos.

- Pleistoceno medio (zona de Corduente, Huertapelayo, y Puente San Pedro). Los edificios asociados a esta fase son los que alcanzan mayores dimensiones.

- Pleistoceno reciente aparecen formaciones tobáceas en la práctica totalidad de los conjuntos kársticos definidos.

- Holoceno.

- Precipitación actual de carbonatos en numerosas surgencias de la zona. 
Hay un hecho que llama poderosamente la atención en el citado cuadro, y es el contraste existente entre las acumulaciones tobáceas actuales y las pretéritas; la precipitación actual al pie de las surgencias y en los cauces de los ríos es muy desigual en unas zonas y otras; pero en todo caso, esta precipitación es de mucha menor importancia de la que se registró en el pasado. ¿Cuáles pueden ser las causas?

Una primera explicación puede apuntar hacia la presencia de elementos polucionantes en las aguas, tales como nitritos, nitratos, fósforo, etc. a los que son tan sensibles las especies higrófilas constructoras de acumulaciones tobáceas, especialmente las algas cianofíceas. En efecto, la Fuente de La Toba de Corduente tiene fama por su facilidad para «construir toba», sin embargo ésta sólo se produce en zonas de abundante insolación, aguas arriba del pueblo, ya que los canales de agua alimentados por la misma surgencia pero situados aguas abajo de Corduente, no presentan ni rastro de precipitación alguna debido a los aportes de aguas residuales que provocan la desaparición de las algas, tal y como se ha advertido en otros parajes (Ordóñez et al., 1980) por la presencia de aguas contaminadas.

Idéntico comentario podría realizarse de los cauces de algunos ríos o alimentados por algunas surgencias. Este es el caso del Gallo y del Tajo. El primero no presenta el más mínimo vestigio de precipitación de carbonatos aguas abajo de Molina de Aragón. El Tajo, apenas se muestra contaminado por nitritos o nitratos y por ello todavía se pueden advertir ciertos procesos de precipitación en algunas zonas de turbulencia (especialmente en el estío) o en zonas de aguas remansadas de las orillas (ver cap. fluvial). No obstante, queda aún por evaluar el papel abrasivo que para la vegetación higrófila del cauce del Tajo (y para los procesos de precipitación) pudiera haber desempeñado la existencia de las enormes explotaciones de caolín situadas aguas arriba y de su consiguiente operación de lavado. Con respecto a algunas surgencias, hemos podido apreciar las modificaciones introducidas en un corto plazo de tiempo por los aprovechamientos piscícolas en el $\mathrm{A}^{\circ}$ Campillo, lo cual aconsejó que dejaramos de tomar datos sobre sus aguas.

En el resto de las surgencias, donde los contaminantes se reducen a mínimas trazas o están ausentes, la moderación y a veces la inhibición que actualmente ofrecen los procesos de precipitación de carbonatos debe ser explicado por otros motivos. El contraste de tamaño y volumen que existe entre los edificios tobáceos antiguos (Pleistoceno/Holoceno) 
y los actuales, incluso el hecho de que magníficos edificios se asienten al pie de surgencias por las que normalmente no hay circulación hídrica (La Escareruela), debe atribuirse a cambios vinculados a la hidrología: disminución actual de los caudales, fuertes pulsaciones en los cauces, por la hidroquímica (cambios en la composición y mineralización de las aguas) o al grado de fitoestabilización de las laderas que ha controlado la cantidad de terrígenos en los flujos de agua; de este modo también podría explicarse la importante precipitación tobácea detectada en algunas zonas como el Barranco de Las Tobas en las proximidades de Huertapelayo, lugar alejado de cualquier tipo de aprovechamiento antrópico y de abundante vegetación.

\section{Consideraciones finales}

Finalmente, hay que hacer referencia a un hecho importante y es el igual desarrollo kárstico de la zona. Efectivamente, la presencia, frecuencia y tamaño de las formas exokársticas de la muela de Villanueva de Alcorón, que es la que reune las manifestaciones más importantes: un antiguo poljé, varias depresiones, etc., no se repite en otras zonas en las que las formas exokársticas están prácticamente ausentes (muelas cretácicas de Lebrancón y parameras jurásicas). Lo mismo ocurre con la localización de simas y cavidades, abundantes en la muela de Villanueva y excepcionales en el resto del territorio. ¿Qué factores pueden explicar este hecho?:

- Puede recurrirse a los factores litológicos siguiendo la explicación de Roglic que explica la ausencia de formas exokársticas como debido a la rareza de capas calizas puras y al predominio de las dolomías, siendo éstas menos solubles que la caliza pura. También dentro de este grupo de razones hay que destacar la presencia en el interior de las muelas, pero especialmente en las parameras jurásicas de tramos margosos.

- La escasa fracturación y tectonización de las parameras jurásicas.

- No hay que olvidar tampoco las posibles razones de tipo paleoclimático, sobre todo a la vista de la desigual repartición de las precipitaciones en la región $(518 \mathrm{~mm}$. de media anual en Molina, coincidiendo con las parameras menos karstificadas y $918 \mathrm{~mm}$. en Villanueva de Alcorón, donde las formas exokársticas y endokársticas están muy desarrolladas). 
- Sin rechazar la influencia de los factores litológico y climático, se puede formular una tercera hipótesis más compleja. La existencia de formas exokársticas en unas zonas y no en otras, está motivada por otros factores ligados a la evolución geológica del sector, ya que extensiones importantes de esta zona estuvieron recubiertas por formaciones detríticas de edad neógena que pudieron otorgar «inmunidad kárstica» a las topografías anteriores. Sin embargo, este factor que podría explicar la ausencia de formas kársticas en amplios sectores de nuestra zona (muela de Lebrancón, sector oriental en las proximidades de Molina), no serviría para el caso de la paramera jurásica de Torremocha, en la que no se ha detectado ningún afloramiento neógeno: aquí además, la existencia de importantes edificios tobáceos relacionados con las surgencias, asociados a las distintas etapas cuaternarias, identifican una importante karstificación, pudiendo ser el factor litológico el que desempeñe en este caso un papel determinante.

Finalmente, hay que señalar un último hecho y es la escasez y delgadez de los mantos de arcillas de descalcificación existentes sobre la topografía culminante de los relieves calizos; aquéllos, cuando aparecen se sitúan en el interior de las depresiones de origen kárstico. Esta rareza se acusa sobre todo en el techo de las parameras jurásicas. En otras zonas, como la muela de Villanueva, las arcillas de descalcificación suelen aparecer con mayor frecuencia aunque casi siempre con un carácter bastante pelicular. Este hecho, junto con una localización de los mantos, lejos de los sumideros e incluso de cualquier punto de infiltración (grandes fisuras, diaclasas ensanchadas por la disolución), tan abundantes en esta zona, sugieren que parte de las arcillas han emigrado en profundidad, aborbidas por las aguas de infiltración.

\section{BIBLIOGRAFÍA}

Alonso, F.; González Martín, J. A., y Ugarte F. (1987): «Sur l'evolution de trois grandes dèpressions karstiques de la Serranía de Cuenca (Espagne)». Mediterranèe, ${ }^{\circ}{ }^{\circ} 1$, pp. 21-32.

Eк, C. (1966): «Faible agressivité de l'eau de fonte des glaciers: l'example de la Marmolada (Dolomites)». Ann. Soc. Geol. Belgique, 89, pp. 177-188.

Fernández Nieto, R.; Fernández Rubio, R.; Gutiérrez Elorza, M., y Arrese Serrano, F. (1983): «Papel de la karstificación en la génesis de los yacimientos de hierro en Sierra Menera (Teruel y Guadalajara)». XVII Curso de Geología Práctica. Teruel, pp: 17-38. 
GonzÁlez Amuchastegui, M. J., y GonzÁLez MARTín, J. A. (1989): «Geomorfología de las formaciones tobáceas del valle del río Gallo en el área de Molina de Aragón». Cuaternario y Geomorfología. Vol. 3, n. ${ }^{\text {os }} 1-4$, pp: 63-72.

GonZÁLEZ AMUCHASTEGUI, M. J. (1993): «Geomorfología del “Alto Tajo" en el sector de Molina de Aragón». Tesis Doctoral, inédita, U. Autónoma de Madrid, 732 págs.

—; GARCÍA GIMÉNEZ, R., y GonZÁleZ MARTÍn, J. A. (1995): «Naturaleza hidrogeográfica de los conjuntos kársticos en la zona de Molina de Aragón y Alto Tajo a partir del estudio de sus surgencias». Anales de Geografía de la Universidad Complutense, 14, pp. 209-224.

—, y GONZÁlez MARTín, J. A. (1993): «Estudio geomorfológico de las acumulaciones travertínicas y tobáceas del Alto Valle del Tajo (Peñalén-Huertapelayo)». 2. ${ }^{a}$ Reunión del Cuaternario Ibérico. El Cuaternario en España y Portugal. I.T.G.E. - A.E.Q.U.A., vol. 1, pp. 99-109.

- (1997): Formaciones tobáceas y modelo de evolución fluvial en El Alto Tajo. Medios carbonatados continentales. Sevilla.

GonzÁlez martín, J. A.; ORdóñez, S., y García del CuRA, M. A. (1987): «Evolución geomorfológica de las Lagunas de Ruidera (Albacete-Ciudad Real)». Est. Geológicos, 43, pp. 227-239.

Goudie, A. S.; Viles, H. A. et Pentecost, A. (1993): «The late-Holocene tufa decline in Europe», The Holocene, 3, 2: 181-186.

GutiéRrez Elorza, M., y PEÑA Monne, J. L. (1975): «Karst y periglaciarismo en la Sierra de Javalambre (Provincia de Teruel)». Bol, Geol. y Minero, t. LXXXVI-VI, pp. 561-572.

— - y — (1979): «El karst de Villar del Cobo (Sierra de Albarracín)». Est. Geológicos, 35 , pp. $651-654$

— - y - (1989): «El karst en la Cordillera Ibérica». El karst en España. Monografía n. ${ }^{\circ}$ 4. Sociedad Española de Geomorfología. Madrid, 23-24 de noviembre de 1989, pp. 151-162.

LHENAFF, R. (1986): «Les grands poljés des Cordillères Bétiques andalouses et leurs rapports avec l'organisation endokarstique». Karstología Mèmoires I-1986, pp. 101-112.

López Vera, F., y Martínez Goytre, J. (1989): «Formación travertínica de Puente San Pedro (Guadalajara). Edad, ambiente de formación y evolución». Bol Geol. y Min., vol. 100-2, pp. 248-258.

MAGNIN, F.; GUENDON, J. L.; VAUdOUR, J. et MARTIN, P. (1991): «Les travertins: accumulations carbonatées associèes aux systèmes karstiques, séquences sédimentaires et paléoenvironnements quaternaires». Bulletin Sociétè géologique de France, 162 (3): 585584 .

MiotKe, F. D. (1968): «Karst morphologische studien in der glazial überformen Höhenstufe der "Picos de Europa" Nordspanien». Selbstuerlag der Geographischen Gesellschaft, Hanover.

NicoD, J. (1981): «Repartition, classification, relation avec les milieux karstiques et karstification. Discussion». Formations carbonatèes externes: tufs et travertins. Assoc. Franç. de karstologie, pp.173-179.

- (1986): «Facteurs physico-chimiques de l'accumulation des formations travertineuses». Mediterranèe, n. ${ }^{\circ}$ 1-2. pp. 161-164

ORDóñEz, S., et al. (1980): "Carbonatos biogénicos actuales en la cuenca del río Dulce (prov. de Guadalajara)». Bol. R. Soc. Esp. de Historia Natural (Geol), 78, pp. 303-315.

-; García del Cura, M. A.; González Amuchastegui, M. J., y GonzÁlez Martín, J. A (1992): «Génesis actual de carbonatos fluviales en el alto valle del río Tajo (prov. de Guadalajara)». III Congreso Geológico de España. Tomo I, pp. 158-163. Salamanca 1992.

Puch, C. (1986): «Karst interno: la sima Juan Herranz 2». En Atlas de Geomorfología. Col. Alianza Atlas. Ed. Alianza, pp. 285-300. 
- (1988): «La sima de Manuel Mozo (Villanueva de Alcorón, Guadalajara) y otras cavidades de la Serranía». Exploracions 12, pp 87-107.

VAUDOUR, J. (1984): «Les travertins de piémont: contribution à l'étude des géosystèmes karstiques méditerranéens». Montagnes et Piémonts R.G.P.S.O., pp. 349-362.

- (1994): «Evolution holocène des travertins de vallée dans le Midi Méditerranéen français». Geographie physique et Quaternaire, vol. 48, n. ${ }^{\circ}$ 3, pp. 315-326.

VAUMAS, E. de (1967): «Phénomènes karstiques en Mediterranée orientel». Mem. et Docum., C.N.R.S., vol. 4, pp. 193-281. 